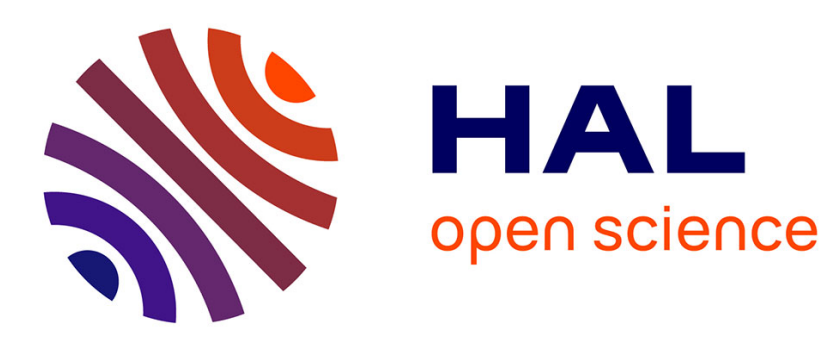

\title{
Investigation of Uniaxial Induced Anisotropy in Co0.02Ni0.58Cd0.20Fe2.20O4 and Co0.02Ni0.58Cd0.20Cr0.20Fe2O4 Ferrites
}

\author{
N. Huong, D. Minh, B. Cong, N. Chau
}

\section{- To cite this version:}

N. Huong, D. Minh, B. Cong, N. Chau. Investigation of Uniaxial Induced Anisotropy in Co0.02Ni0.58Cd0.20Fe2.20O4 and Co0.02Ni0.58Cd0.20Cr0.20Fe2O4 Ferrites. Journal de Physique IV Proceedings, 1997, 07 (C1), pp.C1-229-C1-230. 10.1051/jp4:1997187 • jpa-00255134

HAL Id: jpa-00255134

https://hal.science/jpa-00255134

Submitted on 1 Jan 1997

HAL is a multi-disciplinary open access archive for the deposit and dissemination of scientific research documents, whether they are published or not. The documents may come from teaching and research institutions in France or abroad, or from public or private research centers.
L'archive ouverte pluridisciplinaire HAL, est destinée au dépôt et à la diffusion de documents scientifiques de niveau recherche, publiés ou non, émanant des établissements d'enseignement et de recherche français ou étrangers, des laboratoires publics ou privés. 


\title{
Investigation of Uniaxial Induced Anisotropy in $\mathrm{Co}_{0.02} \mathrm{Ni}_{0.58} \mathrm{Cd}_{0.20} \mathrm{Fe}_{2.20} \mathrm{O}_{4}$ and $\mathrm{Co}_{0.02} \mathrm{Ni}_{0.58} \mathrm{Cd}_{0.20} \mathrm{Cr}_{0.20} \mathrm{Fe}_{2} \mathrm{O}_{4}$ Ferrites
}

\author{
N.T. Huong, D.L. Minh, B.T. Cong and N. Chau \\ Faculty of Physics, Natural Science University, 90 Nguyen Trai, Dong Da, Hanoi-Vietnam
}

\begin{abstract}
The NiCd ferrites with $\mathrm{Fe}$ excess in comparison with stoichiometry composition and with $\mathrm{Fe}$ excess amount substituting by $\mathrm{Cr}$, moreover containing small amount of $\mathrm{Co}$ are prepared. The formation of preminvar effect and uniaxial induced anisotropy in these ferrites are examined under the heat treatment with and without magnetic field. The appearence of uniaxial induced anisotropy causes unexpected changes of some magnetic and electric properties of ferrites.
\end{abstract}

\section{INTRODUCTION.}

A lot of ferromagnetic alloys exhibits the induced anisotropy and their properties are very sensitive with magnetic heat treatment. It was found that the uniaxial induced magnetic anisotropy (UIMA) is also presented in iron-excess nickel ferrites with doping of Co. The directional order theory and single - ion theory suggested by Néel [1], Taniguchi and Yamamoto [2], Chikazumi [3] and Slonczewski [4] are used to explain these phenomena.

The perminvar effect and the magnetic annealing treatment (MAT) of iron-excess NiZnCo [5] and NiCdCo [6,7] ferrites have been investigated.

In this paper, the influence of UIMA on the magnetic and electric properties of iron-excess $\mathrm{NiCd}$ and $\mathrm{NiCdCr}$ ferrites with small doping of $\mathrm{Co}$ is examined.

\section{EXPERIMENT.}

The ferrite samples with compositions :

$\mathrm{N}^{\circ} 1 \quad \mathrm{Co}_{0.02} \mathrm{Ni}_{0.58} \mathrm{Cd}_{0.20} \mathrm{Fe}_{2.20} \mathrm{O}_{4}$

$\mathrm{N}_{2}^{\circ} \quad \mathrm{Co}_{0.02} \mathrm{Ni}_{0.58} \mathrm{Cd}_{0.20} \mathrm{Cr}_{0.20} \mathrm{Fe}_{2} \mathrm{O}_{4}$

are prepared by conventional ceramic technology.

The toroid and parallelepiped samples are sintered at $1280^{\circ} \mathrm{C}$ and the isothermal keeping time is 3 hours. They are slowly cooled from sintering temperature to room temperature with rate $60^{\circ} \div 80^{\circ} \mathrm{C} / \mathrm{h}$. Then they are annealed with $\mathrm{T}_{a n}=0.9 \mathrm{~T}_{c}$ in magnetic field $\mathrm{H}_{\text {an }}>10 \mathrm{H}_{c}$.

The crystallographic structure of materials was checked by X-ray diffractometer Siemens D5000, magnetization and hysteresis loop parameters are measured by VSM and ballistic galvanometer respectively. The tensor-sensor technique is used to measure the longitudinal and transversal magnetostriction.

\section{RESULTS AND DISCUSSION}

After slowly cooling, the local anisotropy in both ferrites is appeared with characteristic perminvar hysteresis loop (Fig.1). During the suitable MAT, uniaxial anisotropy is induced in the sample and hysteresis loop becomes rectangular (Fig.2). Obviously, this UIMA causes the variation in some magnetic, electric properties of samples : the decreasing of initial permeability $\mu_{0}$ and of its temperature coefficient; the increasing of the Curie temperature, maximum permeability $\mu_{m}$, coercivity $\mathrm{H}_{c}$, remanent and maximum induction as well as rectangular coefficient (see Tab.1). Moreover magnetostriction and galvanomagnetic effects are influenced by MAT.

The substitution of iron-excess amount (in sample $\mathrm{N}^{\circ} 1$ ) by $\mathrm{Cr}$ (in sample $\mathrm{N}^{\circ} 2$ ) leads qualitatively to the same influence on ferrites but Curie temperature $T_{c}$ and magnetization are decreasing whereas specific resistance as well as activation energy are increasing. It could be explained that the substitution of $\mathrm{Fe}$ by $\mathrm{Cr}$ ions, the $\mathrm{Fe}^{2+}$ and $\mathrm{Fe}^{3+}$ concentrations in octahedral 
sublattice are decreasing and this brings to reduction of magnetization of B sublattice and electron hopping between Fe ${ }^{2+}$ and $\mathrm{Fe}^{3+}$ also.

Especially the strong increase of dielectric constant $\epsilon$ (for one order) after MAT has been observed. One can suggest that the MAT applied in prepared ferrites creates not only magnetic polarization but also the electric polarization of jon pairs with identical valency (magnetic dipoles) or with different valencies (magnetic dipoles and pseudo-electric dipoles) in octahedral sublattice.

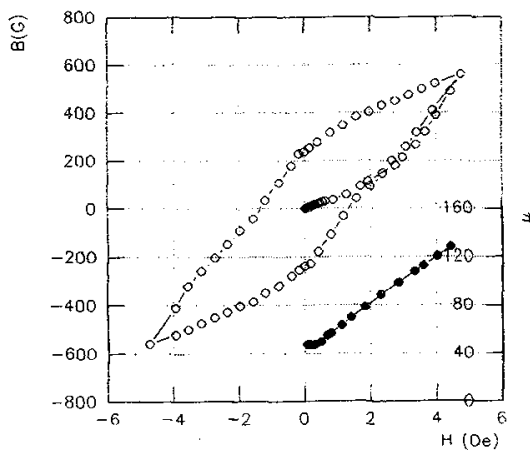

Figure 1. Hysteresis loop of slowly-cooled sample $\mathrm{N}^{\circ} 2$

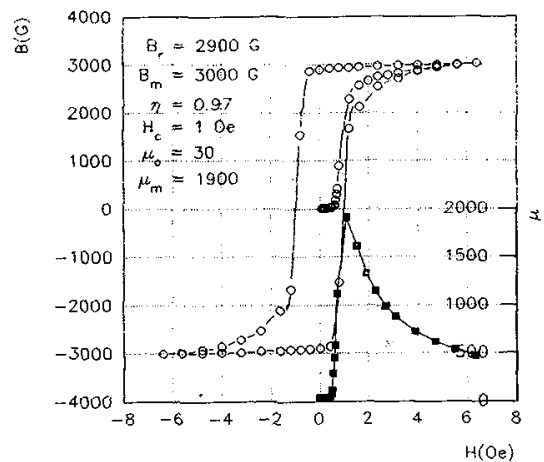

Figure 2. Hysteresis loop of slowly-cooled sample $\mathrm{N}^{\circ} 1$ after MAT

Table 1. Some characteristics of samples $N^{\circ} 1$ and $N^{\circ} 2$ before and after MAT

\begin{tabular}{|c|c|c|c|c|c|c|c|c|c|}
\hline Samples & $\mu_{0}$ & $\mu_{m}$ & $\begin{array}{l}\mathrm{B}_{r} \\
(\mathrm{G})\end{array}$ & $\begin{array}{l}\mathrm{B}_{m} \\
(\mathrm{G})\end{array}$ & $\begin{array}{c}\mathrm{H}_{c} \\
(\mathrm{Oe})\end{array}$ & $\begin{array}{c}\mathrm{T}_{c} \\
\left({ }^{\circ} \mathrm{C}\right)\end{array}$ & $\begin{array}{c}E_{p} \\
(\mathrm{eV})\end{array}$ & $\begin{array}{c}\sigma_{s} \text { at } 77 \bar{K} \\
(\mathrm{emu} / \mathrm{g})\end{array}$ & $\begin{array}{c}\mathrm{a} \\
\left(\mathrm{A}^{\circ}\right)\end{array}$ \\
\hline iv 1 slowiy cooled & $3 \vec{i}$ & $12 T$ & $18 \overline{0}$ & 810 & 1 & 512 & 0.26 & 80 & $\delta .404 t$ \\
\hline $\mathrm{N}^{0} 2$ slowly cooled & 47 & 118 & 238 & 560 & 1.5 & 495 & 0.34 & 76 & 8.3996 \\
\hline $\mathrm{N}^{\circ} 1$ subjected $\mathrm{MAT}$ & 30 & 1900 & 2900 & 3000 & 1 & 526 & 0.17 & 91 & 8.3928 \\
\hline $\mathrm{N}^{\circ} 2$ subjected $\mathrm{MAT}$ & 38 & 1100 & 2600 & 2700 & 1.5 & 500 & 0.23 & 80 & 8.3924 \\
\hline
\end{tabular}

\section{CONCLUSION}

After annealing in magnetic field, the uniaxial induced anisotropy is created in iron excess $\mathrm{NiCd}$ and $\mathrm{NiCdCr}$ ferrites containing small doping of $\mathrm{Co}$. The substitution of $\mathrm{Fe}$ excess by $\mathrm{Cr}$ has remaining general behaviour of ferrites like perminvar effect and UIMA but some parameters are strongly changed. The strong infuence of above mentioned anisotropy on the dielectric constant probably determined by us for the first time.

\section{Acknowledgments}

The authors are grateful to Dr N.X.Phuc from Materials Science Institute (NCNST) for magnetization measurement and to National basic research program on Natural Sciences for financial support.

\section{References}

[1] Néel L., J.Phys.Rad. 15 (1954) 225

[2] Taniguchi S., Yamamoto M., Sci Rep.Res.Inst.Tohoku Univ.,A6(1954)330; A7(1955)269;A8(1956)173

[3] Chikazumi S., J.Phys.Soc.Japan 11 (1956) 551

[4] Slonczewski C., Phys.Rev. 110 (1958) 1341

[5] N.Chau, Doctor thesis. State University of Moscow (1965)

[6] N.Chau, P.Q.Niem, B.T.Cong, Folla Physica 1 (1987) 10

[7] N.Chau et al, Proceedings of the $2^{\text {nd }}$ International Workshop on Materials Science (IWOMS'95) Hanoi Oct.1995, p $426-431$ and $\mathrm{p}$ 660-663. 